\title{
Study of the serum level of fasting glucagon-like peptide-1 in type 2 diabetics and its relation to the glycemic profile Mohamed A. Korani ${ }^{\mathrm{a}}$, Ahmed Sonbol ${ }^{\mathrm{b}}$
}

${ }^{a}$ Assistant Professor of Internal Medicine Department, ${ }^{b}$ Assistant Professor of Clinical Pathology Department, Faculty of Medicine, Menoufia University, Egypt

Correspondence to Mohamed A. Korani, 90 Fawzi Moaz Street, Smoha, Alexandria, 21648, Egypt. Tel: +20 1010903937 ;

e-mail: mohammedelsayed29@icloud.com

Received 20 October 2017 Accepted 31 October 2017

The Egyptian Journal of Internal Medicine 2018, 30:54-57

\begin{abstract}
Background
Glucagon-like peptide-1 (GLP-1) is a peptide formed of 30 amino acids. It is synthesized in and released from the enteroendocrine $L$ cells that are present throughout the small and the large intestine. Because of the important physiological role of GLP-1 in augmenting insulin secretion, it is generally believed that GLP-1 release is deficient in type 2 diabetes mellitus (T2DM) patients.

However, studies in adults have yielded conflicting results showing decreased, normal, or increased GLP-1 concentrations in prediabetics or T2DM after oral glucose or mixed meal.

The aim of this work was to study the level of fasting total GLP-1 in T2DM patients and its relation to the glycemic profile.

Patients and methods

This study included 60 T2DM patients and 40 participants matched for age and sex as a control group, selected from the inpatient and outpatient clinics of the Internal Medicine Department in Menoufia University Hospital. After obtaining their informed consent, all participants were subjected to a full assessment of history and physical examination with estimation of $\mathrm{BMI}$, insulin resistance with homeostasis model assessment-2, and investigations including fasting blood glucose (FBG), glycated hemoglobin (HbAlc), and the total fasting levels of GLP-1.

\section{Results}

There was no significant difference in the level of GLP-1 between T2DM patients and the controls. There were significant negative correlations between the fasting total GLP-1 and FBG, HbAlc, serum insulin, and homeostasis model assessment-2 in both the total sample and the T2DM patients.

Conclusion

Fasting total levels of GLP-1 are not reduced in T2DM patients and are negatively correlated with FBG, HbAlc, and insulin resistance.
\end{abstract}

\section{Keywords:}

glucagon-like peptide-1, glucose homeostasis, type 2 diabetes mellitus

Egypt J Intern Med 30:54-57

(C) 2018 The Egyptian Journal of Internal Medicine

$1110-7782$

\section{Introduction}

The incretin effect is the augmented insulin secretion that is elicited by oral compared with intravenous administration of glucose when glucose levels during two challenges are matched. It is clear that the incretin effect is lower in those with type 2 diabetes mellitus (T2DM) than healthy individuals [1].

The fasting glucagon-like peptide-1 (GLP-1) level in T2DM is still a topic of controversy. Some studies showed that its level is higher in diabetics than in controls [2], some concluded that it is the same in both diabetics and nondiabetics [3], whereas others have reported that it is lower in diabetics than in normal controls [4].

The aim of this work was designed to study the serum level of fasting GLP-1 in T2DM compared with controls, and to determine the relation of this level with the glycemic profile as measured by fasting blood glucose (FBG) and glycated hemoglobin (HbAIc).

\section{Patients and methods}

The Selected patients gave consent for participation in the study before they were exposed to examination and investigations. The protocol of this study was approved by the ethical committee of faculty of Medicine. The study was carried out on 100 participants divided into two groups:

(1) Group 1:60 T2DM patients.

(2) Group 2: 40 healthy controls matched for age and sex.

The patients were recruited from the clinics of Internal Medicine and Diabetes Unit during the period from July 2017 to October 2017.

This is an open access journal, and articles are distributed under the terms of the Creative Commons Attribution-NonCommercial-ShareAlike 4.0 License, which allows others to remix, tweak, and build upon the work non-commercially, as long as appropriate credit is given and the new creations are licensed under the identical terms. 


\section{Exclusion criteria}

(1) Severe renal and hepatic impairment.

(2) Acute illness or malignancy.

(3) T2DM on incretin-based therapy or metformin.

After obtaining their informed consent, all the participants were subjected to the following:

(1) Full assessment of history.

(2) Complete physical examination including body weight, height, and calculation of BMI.

(3) Laboratory assessment including FBG, HbAIc, blood urea and creatinine, serum alanine transaminase, fasting serum insulin level, and fasting serum GLP-1, and assessment of insulin resistance using the homeostasis model assessment-2 (HOMA2) calculator according to the HOMA2 model in participants with normal and impaired glucose tolerance.

\section{Statistical method}

Statistical analyses were carried out using SPSS software (IBM Corp., IBM SPSS Statistics for Windows, version 18.0, Armonk, NY: IBM Corp., Chicago, USA).

Quantitative data were presented as mean \pm SD. The statistical significance between means was estimated using the Mann-Whitney test and Student's test. Spearman's correlation coefficient was used to measure the strength of the association between two numerical variables. Differences were considered statistically significant at a $P$ value of less than or equal to 0.05 .

\section{Results}

The study included 60 patients with T2DM and 40 healthy participants as a control group.
The FBG, HbAIc, fasting serum insulin, and HOMA2 were significantly higher in group 1 compared with group 2, whereas there was no significant difference between the two groups in BMI (Table 1).

There was no statistically significant difference between both groups in the total fasting levels of GLP-1 (Table 2).

There were significant negative correlations between the total GLP-1 levels and FBG, HbAIc, fasting serum insulin, and HOMA2, and no significant correlation between GLP-1 level and BMI (Table 3).

\section{Discussion}

GLP-1 is synthesized and released from the enteroendocrine $\mathrm{L}$ cells that are present throughout the gut [5]. Together with the glucose-inhibitory polypeptide, they account for the incretin effect, which is uniformly defective in T2DM patients $[6,7]$.

The current study showed that there was no statistically significant difference in the GLP-1 levels between the diabetic group and the controls; this is in agreement with what was reported by Yabe et al. [3], who found that the total fasting levels of GLP-1 showed no significant difference between T2DM patients and healthy individuals. Also, a meta-analysis including 22 studies carried out by Calanns et al. [8] showed that were no significant differences in the total fasting GLP-1 levels between T2DM patients and controls. Lastya et al. [4] reported that the fasting GLP-1 level was significantly lower in participants with T2DM than those with normal glucose tolerance, which is not in agreement with our results, and explained this difference by

Table 1 Comparison between the studied groups according to the clinical and laboratory data

\begin{tabular}{|c|c|c|c|c|}
\hline & Group $1(n=60)$ & Group $2(n=40)$ & Tests of significance & $P$ value \\
\hline $\mathrm{FBG}(\mathrm{mg} / \mathrm{dl})$ & $164.07 \pm 56.08$ & $83.89 \pm 9.16$ & $M W=3.832$ & $<0.001^{*}$ \\
\hline $\mathrm{HbAIC} \mathrm{( \% )}$ & $7.94 \pm 1.89$ & $5.39 \pm 0.23$ & $t=8.477$ & $<0.001^{*}$ \\
\hline Fasting serum insulin $(\mu \mathrm{l} / \mathrm{ml})$ & $14.8 \pm 4.55$ & $3.1 \pm 1.60$ & $M W=2.920$ & $0.003^{*}$ \\
\hline HOMA2 & $7.70 \pm 6.0$ & $2.03 \pm 0.91$ & $M W=2.783$ & $0.005^{\star}$ \\
\hline Serum creatinine (mg/dl) & $0.87 \pm 0.29$ & $0.88 \pm 0.118$ & $t=0.207$ & 0.836 \\
\hline $\operatorname{ALT}(\mathrm{U} / \mathrm{I})$ & $36.86 \pm 11.75$ & $34.55 \pm 11.10$ & $t=0.984$ & 0.327 \\
\hline BMI $\left(\mathrm{kg} / \mathrm{m}^{2}\right)$ & $26.7 \pm 4.8$ & $25 \pm 5$ & $t=1.706$ & 0.091 \\
\hline
\end{tabular}

ALT, serum alanine transaminase; FBG, fasting blood glucose; HbA1C, glycated hemoglobin; HOMA2, homeostasis model assessment; MW, Mann-Whitney test; $t$, Student's test. $P \leq 0.05$, statistically significant. *Statistically significant.

Table 2 Comparison between the groups studied according to the fasting total glucagon-like peptide-1 level

\begin{tabular}{lcccc}
\hline & Group $1(n=60)$ & Group $2(n=40)$ & $P$ value \\
\hline Fasting total GLP-1 $(\mathrm{pg} / \mathrm{ml})$ & $629.60 \pm 240.40$ & $601 \pm 201.10$ & $\mathrm{MW}=0.611$ & 0.541 \\
\hline
\end{tabular}

GLP-1, glucagon-like peptide-1; MW, Mann-Whitney test. $P \leq 0.05$, statistically significant. 
Table 3 Correlation between the fasting total glucagon-like peptide-1 and other parameters in the studied groups

\begin{tabular}{lccccc}
\hline & \multicolumn{2}{c}{ Total } & $(n=100)$ & & \multicolumn{2}{c}{ Group 1} & $(n=60)$ \\
\cline { 2 - 3 } \cline { 5 - 6 } & $r$ & $P$ & & $r$ & $P$ \\
\hline FBG & -0.295 & 0.005 & & -0.281 & 0.028 \\
HbAIC & -0.275 & 0.009 & & -0.388 & 0.002 \\
HOMA2 & -0.561 & $<0.001$ & & -0.577 & $<0.001$ \\
Fasting serum insulin & -0.465 & $<0.001$ & & -0.508 & $<0.001$ \\
BMI & 0.095 & 0.205 & & 0.205 & 0.068 \\
\hline
\end{tabular}

FBS, fasting blood glucose; $\mathrm{HbA1C}$, glycated hemoglobin; HOMA2, homeostasis model assessment. $P \leq 0.05$, statistically significant.

suggesting impaired GLP-1 release and accelerated GLP-1 metabolism in T2DM participants.

In contrast to our results, Alssema et al. [2] reported that fasting levels of GLP-1 were significantly higher in T2DM patients in comparison with normoglycemic participants and explained that higher levels of fasting GLP-1 may reflect a compensatory mechanism to overcome generalized impairment of beta cell response and function.

The present study found no significant correlation between fasting GLP-1 levels and BMI, in agreement with the finding reported by De Luis et al. [9], who found no significant correlation between GLP-1 levels and BMI in obese patients with metabolic syndrome. The same was also reported by Zhang et al. [10], who found no significant correlation between fasting GLP-1 levels and either BMI or waist circumference among T2DM patients and prediabetics.

The weight-decreasing effect of GLP-1 because of enhanced satiety and delayed gastric emptying is suggested to occur with high or supraphysiological GLP-1 levels, whereas low levels of GLP-1 have lipogenic effects on adipocytes [11]. In the current study, we found a significant negative correlation between GLP-1 levels and FBG in the total sample and in diabetics; this is in agreement with the result reported by Vilsbøll et al. [12], who found that GLP-1 is insulinotropic even at basal glucose levels. Also, Umeda et al. [13] found that FBG improved significantly in T2DM patients after bariatric surgery and showed that the improvement is related to increased GLP-1 release.

However, Yamaoka-Tojo et al. [14] found that there was no significant relation between fasting GLP-1 levels and FBG in T2DM patients and prediabetics. The difference between the result of this study and the study of Yomaoka-Tojo et al. [14] may be related to the difference in participant characteristics as their study included some patients with coronary artery disease, liver disorders, and chronic kidney disease, which may affect GLP-1 levels and their relationship with FBG.

The current study found a significant negative correlation between GLP-1 levels and HbAIc in the total sample and diabetics. Sista et al. [15] showed that there was a significant negative correlation between fasting GLP-1 and HbAIc in T2DM patients who are subjected to bariatric surgery and followed up for 2 years. However, Hattori et al. [16] and Yamaoka-Tojo et al. [14] found no significant correlation between the two variables. The difference between the results of the studies may be explained by the difference in the characteristics of the participants, racial factors, and sample size, which may affect the relation between the two variables.

There are two mechanisms by which GLP-1 decreases plasma glucose: the first one is insulin dependent and the second is insulin independent, which is mediated through the glucagon-suppressing effect of GLP-1. Hare et al. [17] found that the glucagonostatic and insulinotropic effects of GLP-1 contribute equally toward its glucose-lowering effect.

In this study, there was a significant negative correlation between GLP-1 levels and insulin resistance as measured by fasting serum insulin and HOMA2; this is in agreement with a recent study carried out on T2DM patients in China by Wang et al. [18] A significant negative correlation was found between fasting GLP-1 and insulin resistance. However, Yabe et al. [19] found that there was no significant correlation between GLP-1 and insulin resistance in obese patients with metabolic syndrome; a few investigators have shown that numerous high-affinity GLP-1 binding receptors are expressed on the insulin-sensitive tissues [10], but the relation between endogenous GLP-1 and insulin resistance still needs to be investigated further.

\section{Conclusion}

The levels of fasting total GLP-1 are not significantly different in T2DM patients compared with health individuals, and fasting GLP-1 is significantly and negatively correlated with FBG, HbAIc, and insulin resistance.

\section{Financial support and sponsorship}

Nil. 


\section{Conflicts of interest}

There are no conflicts of interest.

\section{References}

1 Ahrén B. Incretin dysfunction in type 2 diabetes: clinical impact and future perspectives. Diabetes Metab 2013; 39:195-201.

2 Alssema M, Rijkelijkhuizen JM, Holst JJ, Teerlink T, Scheffer PG, Eekhoff EM, et al. Preserved GLP-1 and exaggerated GIP secretion in type 2 diabetes and relationships with triglycerides and ALT. Eur J Endocrinol 2013; 169:421-430

3 Yabe D, Kuroe A, Lee S, Watanabe K, Hyo T, Hishizawa M, et al. Little enhancement of meal-induced glucagon-like peptide-1 secretion in Japanese: comparison of type-2 diabetes patients and healthy controls. J Diabetes Investig 2010; 1:56-59.

4 Lastya A, Saraswati MR, Suastika K. The low level of glucagon-like peptide-1 (glp-1) is a risk factor of type 2 diabetes mellitus. BMC Res Notes 2014; 7:849.

5 Campbell JE, Drucker DJ. Pharmacology, physiology, and mechanisms of incretin hormone action. Cell Metab 2013; 17:819-837.

6 Deacon CF, Ahrén B. Physiology of incretins in health and disease. Rev Diabet Stud 2011; 8:293-306.

7 Nauck MA, Meier JJ. The incretin effect in healthy individuals and those with type 2 diabetes: physiology, pathophysiology, and response to therapeutic interventions. Lancet Diabetes Endocrinol 2016; 4:525-536.

8 Calanna S, Christensen M, Holst JJ, Laferrère B, Gluud LL, Vilsbø\|l T, et al. Secretion of glucagon-like peptide- 1 in patients with type 2 diabetes mellitus: systematic review and meta-analyses of clinical studies. Diabetologia 2013; 56:965-972.

9 De Luis DA, Aller R, Conde R, Primo D, Izaola O, Castro MJ, et al. Basa glucagonlike peptide 1 levels and metabolic syndrome in obese patients. J Investig Med 2012; 60:874-877.

10 Zhang F, Tang X, Cao H, Lü Q, Li N, Liu Y, et al. Impaired secretion of total glucagon-like peptide-1 in people with impaired fasting glucose combined impaired glucose tolerance. Int J Med Sci 2012; 9:574-581.
11 Vander Stouwe JG, Aeschbacher S, Krisai P, Schoen T, Meyre P, Todd J, et al. Plasma levels of glucagon-like peptide 1 and markers of obesity among young and healthy adults. Clin Endocrinol (Oxf) 2015; 83: 636-642.

12 Vilsbøll T, Krarup T, Madsbad S, Holst JJ. Both GLP-1 and GIP are insulinotropic at basal and postprandial glucose levels and contribute nearly equally to the incretin effect of a meal in healthy subjects. Regul Pept 2003; 114:115-121.

13 Umeda LM, Silva EA, Carneiro G, Arasaki CH, Geloneze B, Zanella MT, et al. Early improvement in glycemic control after bariatric surgery and its relationships with insulin, GLP-1, and glucagon secretion in type 2 diabetic patients. Obes Surg 2011; 21:896-901.

14 Yamaoka-Tojo M, Tojo T, Takahira N, Matsunaga A, Aoyama N, Masuda T, et al. Elevated circulating levels of an incretin hormone, glucagon-like peptide-1, are associated with metabolic components in high-risk patients with cardiovascular disease. Cardiovasc Diabetol 2010; 9:17.

15 Sista F, Abruzzese V, Clementi M, Carandina S, Amicucci G. Effect of resected gastric volume on ghrelin and GLP-1 plasma levels: a prospective study. J Gastrointest Surg 2016; 20:1931-1941.

16 Hattori A, Kawamura I, Yamada Y, Kanamori H, Aoyama T, Ushikoshi H, et al. Elevated plasma GLP-1 levels and enhanced expression of cardiac GLP-1 receptors as markers of left ventricular systolic dysfunction: a crosssectional study. BMJ Open 2013; 3:e003201.

17 Hare KJ, Vilsbøll T, Asmar M, Deacon CF, Knop FK, Holst JJ, et al. The glucagonostatic and insulinotropic effects of glucagon-like peptide 1 contribute equally to its glucose-lowering action. Diabetes 2010; 59: 1765-1770.

18 Wang XL, Ye F, Li J, Zhu LY, Feng G, Chang XY, et al. Impaired secretion of glucagon-like peptide 1 during oral glucose tolerance test in patients with newly diagnosed type 2 diabetes mellitus. Saudi Med J 2016; 37:48-54.

19 Yabe D, Watanabe K, Sugawara K, Kuwata H, Kitamoto Y, Sugizaki K, et al. Comparison of incretin immunoassays with or without plasma extraction: incretin secretion in Japanese patients with type 2 diabetes. J Diabetes Investig 2012; 3:70-79. 